\title{
Developing your career in obstetrics and gynaecology
}

\author{
Jacqui Wise
}

London, UK

A career in obstetrics and gynaecology can be stimulating and rewarding. The specialty is wide ranging and there are opportunities to pursue different career paths depending on your interests and abilities.

\section{Advanced training}

In years six and seven of specialty training, trainees undertake advanced training skills modules (ATSMs) or subspecialty training. The choice of ATSM is important as it will determine the special interests you follow in future consultant posts. You only need to complete two ATSMs to gain your certificate of completion of training (CCT) but if resources allow you can complete additional ones.

There are 20 ATSMs to choose from. ${ }^{1}$ They are acute gynaecology and early pregnancy; advanced labour ward practice; advanced laparoscopic surgery for the excision of benign disease; benign abdominal surgery: open and laparoscopic; benign gynaecological surgery: hysteroscopy; clinical research; colposcopy; fetal medicine; high risk pregnancy; labour ward lead; medical education; menopause; obstetric medicine; oncology; paediatric and adolescent gynaecology; safe practice in abortion care; sexual health; subfertility and reproductive health; urogynaecology and vaginal surgery; and vulval disease

\section{Subspecialty training}

Subspecialists in obstetrics and gynaecology are those who have higher training and are recognised to have expertise in a particular field. You can apply for a subspecialty training post at any stage after completing intermediate training and passing the part 2 membership of the Royal College of Obstetricians and Gynaecologists examination. Posts are advertised in The BMJ.

Subspecialty training is a minimum three year programme with two years of clinical training and 12 months of dedicated research. There are four subspecialties available. ${ }^{2}$ These are: gynaecological oncology; maternal and fetal medicine; reproductive medicine; and urogynaecology. You will normally keep doing on-call work during subspecialty training.

\section{Less than full time training}

It is possible to apply for less than full time training, funded by your regional postgraduate dean or through job sharing. Around $20 \%$ of trainees are in such schemes.

\section{Inclusion on the specialist register}

On successful completion of training you can apply for a CCT. The Royal College of Obstetricians and Gynaecologists (RCOG) will then recommend you to the GMC for inclusion on the specialist register. There are several different types of consultant. Some will specialise and only work within obstetrics or gynaecology. Others will work across the specialty within a hospital setting but will concentrate their practice in line with their interests. Others will work predominantly in the community, providing an out of hospital service.

\section{SAS doctor roles}

There are opportunities to work at non-consultant level—for example, as a specialist and associate specialist (SAS) doctor. The role can vary depending on experience. It may involve working on complex surgery or relatively minor diagnostic and outpatient work. SAS doctors are more likely to carry out routine or elective surgery than emergency work. SAS roles can be attractive because of their regular hours and overtime payments for on-call work.

\section{Continuing professional development}

All doctors in non-training grades need to take part in continuing professional development (CPD) and to revalidate to show they are up to date and fit to practise. Revalidation is every five years. Since summer 2019 the RCOG has a new CPD framework and e-portfolio to support it. ${ }^{3}$

\section{Managerial roles}

There are a number of managerial opportunities for consultants. These include being the lead NHS consultant for the team (clinical lead), being the lead NHS consultant for the department (clinical director), or being the lead NHS consultant for the trust (medical director).

\section{Education and training}

Most NHS consultants will be involved with the clinical and educational supervision of junior doctors, and there are also other opportunities.

These include being the NHS consultant responsible for the postgraduate medical training in a hospital (director of medical education), the NHS consultant overseeing the education of the local cohort of trainee doctors (training programme director-for 
instance, foundation training programme director), or the NHS consultant responsible for the management of the entirety of a training programme (associate dean).

\section{Academic pathways}

Many trainees undertake a period of between one and three years in a research post. This can be the impetus to proceed down a pathway of training and develop an area of interest as a consultant. Those with an interest in research may want to consider an academic career in obstetrics and gynaecology.

The usual route for an academic career is through an academic clinical fellowship (ACF) and then to a clinical lectureship. Applications for ACF posts are coordinated by the National Institute for Health Research Trainees Coordinating Centre. ${ }^{4}$ There have been developments in recent years in the areas of cervical cytology, family planning, fertility treatment, hormone replacement therapy, minimal invasive techniques, molecular genetics, and ultrasound.

\section{Working overseas}

A career in obstetrics and gynaecology provides opportunities to work overseas. Volunteers can make a real difference to women's healthcare in low resource countries while gaining valuable skills and experience. The RCOG advertises a number of volunteering opportunities. ${ }^{5}$ Voluntary Service Oversees provides opportunities for specialist trainees and consultants to improve maternal health in developing countries. ${ }^{6}$ Médecins Sans Frontières is also looking for obstetricians and gynaecologists to help with their programmes. ${ }^{7}$

1 Royal College of Obstetricians and Gynaecologists. ATSMs. www.rcog.org.uk/en/careerstraining/specialty-training-curriculum/atsms.

2 Royal College of Obstetricians and Gynaecologists. Subspecialty training. www.rcog.org. uk/en/careers-training/specialty-training-curriculum/subspecialty-training.

3 Royal College of Obstetricians and Gynaecologists. CPD and revalidation. www.rcog.org. uk/en/cpd-revalidation.

$4 \quad$ National Institute for Health Research. www.nihr.ac.uk.

5 Royal College of Obstetricians and Gynaecologists. Get involved in RCOG global health. www.rcog.org.uk/en/global-network/get-involved-in-rcog-global-health.

6 Royal College of Obstetricians and Gynaecologists. RCOG/VSO partnership. www.rcog. org.uk/en/global-network/centre-womens-global-health/rcogvso-fellowship.

7 Médecins Sans Frontières. Medical doctor. www.msf.org.uk/job-profiles/medical-doctor. Published by the BMJ Publishing Group Limited. For permission to use (where not already granted under a licence) please go to http://group.bmj.com/group/rights-licensing/ permissions 